\title{
The Suitable Fabric for Thai Art Folding of Banana Leaves on Clothing
}

\section{Chanakarn Ruangnarong}

Program in Design Arts Graduate School, Faculty of Decorative Arts, Silpakorn University

Email: rchanakarn@yahoo.com

\begin{abstract}
Thailand has a uniquely long-standing tradition of arts and crafts. Thai art folding of banana leaves, probably the best-known such as food wrappers and precious handicrafts has been practiced to make colorful decorations for festivals. As time passed, roles of using parts of banana have been reduced but there has been an attempt to help conserve it only some art and craftsmanship. This research will study and analyze about Thai art folding of banana leaves, the folding technic from art and design, product and fashion for diversity of folding. Furthermore, Fabric is the key of this research to know the type of fabric suitable for folding. Thus, the experiment and practice show the fabric qualification by selected 9 properties included 1. Good stability 2. Good draping 3. Heat resistance 4. Smoothness 5. Balance 6. Wrinkle 7. Stretch 8. Strong 9. Soft with the wearable fabric are 1. Natural Fabric 1.1) Cotton 1.2) Linen 1.3) Muslin 1.4) Jute 1.5) Ramie 2.Man-made fabric 2.1) Polyester 2.2) Nylon 2.3) Organza 2.4) Satin 3. Blended Fabric 3.1) Cotton Spandex 3.2) Linen Viscose. The result is Polyester, Cotton Spandex and Linen Viscose respectively suitable for folding. In conclusion, the purpose of this research compiles the theory, technique, and method of Thai art folding of banana leaves. Moreover, the many types of folding technique from Thai art folding of banana leaves for clothing construction that can be a guideline and modified in the next stage for designers who interested in craftsmanship, culture, and tradition. Then, to create the guideline from the Thai art folding of banana leaves. Finally, the wearable art by using the clothing construction guideline from the Thai art folding of banana leaves.
\end{abstract}

Keywords: fabric, folding, wearable art, traditional techniques

\section{INTRODUCTION}

Considering plants that have been closely linked to the traditional Thai ways of life, banana can be placed among the top ranks. This is not only because its parts are used in many traditional ceremonies but also due to the high nutritive value of its fruit that has made it a simple home remedy or a quick fix for flagging energy levels. Also, banana is a very useful plant to the Thai household. To begin with, most parts of the plant can be used 
for various purposes as explained below. Leaf and stem of banana, in former times, was linked to and became an important part in the Thai ways of life from birth to death. When a mother delivered a baby, there was a ritual of presenting offerings to a midwife as an auspicious start for the new mother and the new baby. At this stage, banana was a must as a part of the offerings. Today, as formerly, when a baby starts to eat, its first food is bananas as it is considered a fruit of high nutrition which is friendly to its digestive system. As children grow up, some parts of the banana can be made into simple toys. A banana stem is cut and made into a toy horse or a gun for children to play with, and the leaf can be woven into animals, such as a centipede and tapian fish; it can also be folded into an oboe. Generally, a banana leaf can also be used as an umbrella because of its large size, or used to wrap food or things and to cover soil to prevent evaporation of its moisture. Moreover, leaf of a kind of banana called tani is used as cigarette papers and those of wild bananas can be used as a temporary roof of a house. The fibrous outer layer of the stem of the banana plant is left to dry, split into strips, and used as ropes to tie things such as vegetables. Apart from being a nutritious food for babies as mentioned above, banana is proven as possessing many curative properties as it contains various kinds of vitamins and minerals. Thus, it can help overcome and prevent many kinds of illnesses and ailments; the abundant nutritional contents explain some benefits of eating bananas (Blue Lotus, 2004).

Thailand has a uniquely long-standing tradition of arts and crafts. Unlike most of its neighbors, it has never been occupied by a foreign power or engaged in wars of conquest, and it has thus enjoyed a relatively peaceful development since ancient times. Patronized by the court and the temples, the designs and craftsmanship of Thai artisans have flourished (William Warren, 1994: 1). Thai banana leaves folding, probably the best-known example of Thailand's precious handicrafts, has been practiced to make colorful decorations for festivals. Leaves are folded in delicate, triangular and intricate patterns before being presented to Lord Buddha statues at temples. The religious offerings made from banana leaves and flower petals are called "Bai Sri". The art of banana leaf folding is handed down from generation to generation (Artcrumps, 2013).

According to archaeological evidence in "Twelve-Month Royal Ceremony" book as a literary work by the King Rama V, krathong was first created by Tao Sri Chulalak or Nang Noppamas in Sukothai, she created a valuable handicraft called krathong with banana leaves, flowers, and carved fruit to worship the goodness of river, Pra mae Khong Ka (Chatchai Wilailuck:2007). Luckily, with the talent of Nang Noppamas, a note of her story, creation, and handicrafts has been made. Therefore, we had the opportunity to know that krathong, the art of banana leaves folding and flowers arrangement of Thailand that has begun in Sukhothai (Maneerat Jantanapalin: 1983). Since Ratanakosin Era, Thai people have admired the aforementioned craftsmanship. The King Rama V liked it very 
much and every queen was interested in it. Queen Saovabha Phongsri trained governors and teachers of Rajini School about the art of banana leaves folding, flower, and dry flower. Furthermore, the Queen supported the art of banana leaves and flowers; new techniques for banana leaves folding and flowers arrangement art were adapted by the queen herself (Jantana Suwanmalee: 1986). On the other hand, Thai people no less overlook their precious things than accept some culture from another country. (Maneerat Chantanapalin: 1997)

As time passed, roles of using parts of banana as such materials as food wrappers or children toys, as well as its role in some ceremonies, have been reduced, and mostly replaced by plastics or other easier-to-find materials. However, there has been an attempt to help conserve the art of decoration from parts of banana, especially for traditional ceremonial purposes, as it is considered a fine art from ancient Thai folk wisdom (Blue Lotus, 2004). Also, Thai banana leaf folding is one of the remaining traditional art that still exist and are known by some art and craftsmanship student, so proliferation is the way to inherit and develop the Thai culture (Pattrawut Thongyam: 2005).

However, a Thai fashion designer, Wisharawish Akarasantisook, his unique concept is high level of craftsmanship in little details (Monruedee Jansuttipan: 2012). He contemplates the abstract and extracts its very essence into the material through technical experiment; the latter at times becomes the main narrative of his fashion design. Championing technical mastery, immaculate handicrafts, and intricate details on pattern, He plays with repetition of forms and geometric shape (Gennaio: 2015). Furthermore, he always uses Thai wisdom in his collection because he is concerned about Thai culture, Thai tradition, and handicraft skill, being aware that it is going to exhausting then if no one use it (Wisharawish: 2015).

In conclusion, this research will study and analyze about Thai art folding of banana leaves, the folding technic from art and design, product and fashion for diversity of folding. Furthermore, Fabric is the key of this research to know the type of fabric suitable for folding.

\section{MATERIAL AND TOOLS}

\section{Materials}

First, fabric and apparel design, commonly referred to as fashion clothing, relates the physical properties of fabric to human need for functional, occasional and fashionable clothing. Materials combine the art and design, the science for support the fabrics suit for the many types of clothing. Second, fashion designers must have the sense by the aesthetic, function and form to be offered a challenging and concentrated foundation in design, drawing, pattern making, construction and fabric analysis. Finally, the types of fabric is 
important for clothing design. The folding experiment by choosing the suitable and fashionable fabric for clothing to folding according to Thai art folding of banana leaves. Fabric divide to 3 types by the manufacturing processes as natural fabric, man-made fabric and blended fabric as fallow.

\section{Natural Fabric}

1) Cotton is the fibrous covering of cotton seeds; these fibers vary widely in length (staple). Cotton is generally off-white to tan in color, but is usually bleached white. Cotton is very absorbent but dries slowly, can withstand high temperatures and vigorous agitation, and dyes easily. It is the most widely used fiber in the world; cotton fabrics range from coarse canvas to the finest batiste. (Holly Brackmann, 2006. The surface designer's handbook. Retrieved from https://books.google.co.th)

2) Linen is the oldest known fabric, with examples dating back to 6000 B.C.E.; its fiber, called flax, comes from the stem of the flax plant. Linen is naturally light cream to gray and very durable. It absorbs water readily and dries faster than cotton. It is stronger when wet than when dry, but it has little resilience and therefore wrinkles easily. Linen can be machine-washed and dried; in fact, repeated washing and ironing makes it lustrous. But because it is subject to abrasion, stored fabrics should be refolded periodically to even out wear. (Holly Brackmann, 2006. The surface designer's handbook. Retrieved from https://books.google.co.th)

3) Muslin is a cotton fabric of plain weave. It is made in a wide range of weights from delicate sheers to coarse sheeting. It gets its name from the city of Mosul, Iraq, where it was first manufacted. Early muslin was handwoven of uncommonly delicate handspun yarn, especially in the region around Dhaka of what today is Bangladesh. It was imported unto Europe for much of the $17^{\text {th }}$ and early $18^{\text {th }}$ centuries. (Muslin. In Wikipedia. Retrived August 12, 2016 from https://en.wikipedia.org/wiki/muslin)

4) Jute is a long, soft, shiny vegetable fiber that can be spun into coarse, strong threads. Jute is one of the most affordable natural fibers and is second only to cotton in amount produced and variety of uses of vegetable fibers. (Jute. In Wikipedia. Retrived August 12, 2016 from https://en.wikipedia.org/wiki/Jute)

5) Ramie, naturally white, comes from the stem of a plant in the nettle family. It is the strongest of the cellulose fibers and dyes easily. Like those of linen, the fibers are not resilient or elastic, and so the fabric wrinkles easily, but it absorbent and dries quickly. (Holly Brackmann, (2006). The surface designer's handbook. Retrieved from https://books.google.co.th) 


\section{Man-made fabric}

1) Polyester was developed in 1941 and today is second to cotton in usage. It is often blended with cotton, linen, or wool, but is also used alone either as fiber or as fiberfill for insulation. It is a very strong fabric, resistant to abrasion, wrinkling, and frequent washing. As with nylon, pleats and other shapes can be permanently set with heat. Polyester microfiber produces fabrics with improved hand, drape, and texture that more closely resemble silk than do regular polyester fabrics. Low absorbency means that polyester dries quickly. Trade name include Dacron, Mylar, Trevira, Ploar Fleece, and Polartec. Some if the latter two fabrics are sometimes made of recycled plastic bottles. Polyester can be dyed only with disperse dyes. (Holly Brackmann, (2006). The surface designer's handbook. Retrieved from https://books.google.co.th)

2) Nylon (polyamide), developed in 1935, was the first synthetic fiber. Although first used for women's stockings, its major uses today, because of its lightness and strength, include carpenting, tent, and backpacks. Nylon has good abrasion resistance and flexibility. It is more absorbent than other synthetic fibers but is damaged by sunlight. Nylon can be dyed with acid, disperse, and vat dyes. Pleats and other folds can be permanently set with heat. (Holly Brackmann, (2006). The surface designer's handbook. Retrieved from https://books.google.co.th)

3) Silk organza used in the resist-scouring process, is stiff because the fabric still contains sericin. The highest quality, most lustrous silk is obtained by killing the silk moth in the cocoon and reeling, or unwinding the filament and degumming it. If the moth is allowed to emerge from the cocoon, it will cut the filament as it exits; the resulting short fibers are used to make noil (raw silk), which has less luster than reeled silk. (Holly Brackmann, (2006). The surface designer's handbook. Retrieved from https://books.google.co.th)

4) Satin is a weave that typically has a glossy surface and a dull back. The satin weave is characterized by four or more fill or weft yarns floating over a warp yarn or vice versa, four warp yarns floating over a single weft yarn. A satin fabric tends to have a high luster due to the high number of floats on the fabric. Because of this it is used in making bed sheets. Many variations can be made of the basic satin weave including a granite weaves are the three basic types of weaving by which the majority of woven products are formed. Satin is commonly used in apparel: satin baseball jackets, athletic shorts, women's lingerie, nightgowns, blouses, and evening gowns, but also in some men's boxer shorts, briefs, shirts and neckties. (Satin. In Wikipedia. Retrived August 12, 2016 from https://en.wikipedia.org/wiki/satin) 


\section{Blended Fabric}

1) Cotton Spandex is a synthetic fiber known its exceptional elasticity, it is stronger and more durable than natural rubber then, its blend with cotton. It revolutionized many areas of the clothing industry. Because of its elasticity and strength (stretching up to five times its length), spandex has been incorporated into a wide range of garments, especially in skin-tight garments. A benefit of spandex id its significant strength and elasticity and its ability to return to the original shape after stretching and faster drying than ordinary fabrics. (Priya Murad: 2016)

2) Linen Viscose is used in combination with viscose. Fabrics with linen like texture and coolness but with good wrinkle recovery can be produced from manufactured fibers and blends. Luster vary from very bright to very dull and can be controlled by addition of de-lust rants in viscose solution moreover greater elasticity than cotton and linen. Linen viscose crease easily although special crease resistant can be applied. Good conductor of heat hence appropriate for summer clothing. One of the most absorbent of all textile which even facilitates dyeing and processing and do not fet damages by weak alkali solutions but strong alkalis cause swelling of fibers and loss strength. (Priya Murad: 2016)

\section{Tools}

1. Sewing machine, Lock stitch type 301

2. Scissors

3. Thread

4. Steam Iron

5. Questionnaire

\section{METHOD}

3.1 Collect documents to define the scope of the study.

3.2 Study about The Thai art folding of banana leaves.

3.3 Study about suitable fabric for fashion folding.

3.4 Experiment and practice The Thai art folding of banana leaves with 11 kinds of fabric with 12 overlapping folding method

3.5 Practicing folding technic and analyze for create folding technic suit for art form in many ways.

3.6 Analyze from study and experiment of The Thai art folding of banana leaves. 


\section{A research methodology}

\section{The suitable fabric for Thai art folding of banana leaves on clothing}

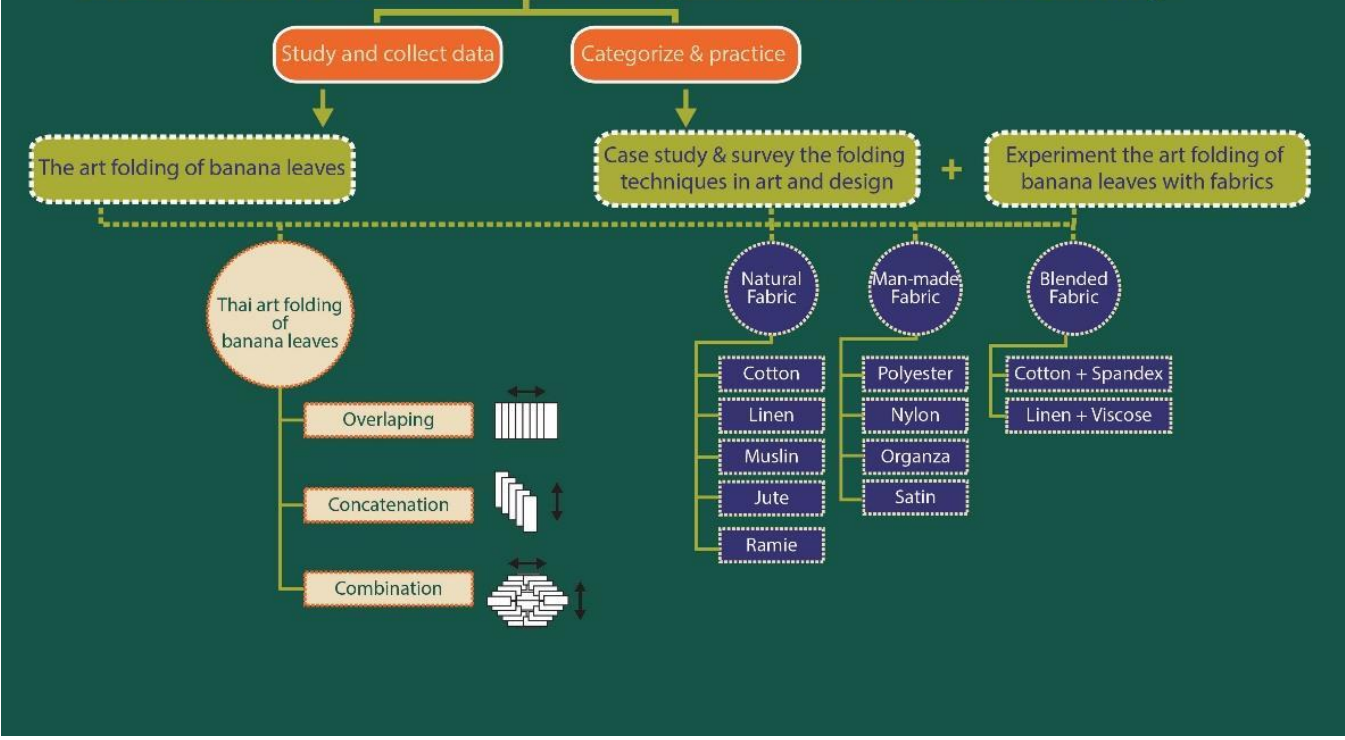

Figure 1. A research methodology of the suitable fabric for Thai art folding of banana leaves on clothing

The 12 types of Thai art folding of banana leaves by overlapping method

1) Hak kor ma

2) Hua kwhan plang

3) Hua nok kor yak

4) Hak kor ma lie pia

5) Kleab fun pla

6) Kleab ku larb yam

7) Kleab ka ra wake

8) Kleab phee seua

9) Kleab ko sol sroy

10) Kleab pood tarn

11) Kleab rat cha pruk

12) Kleab puang ko men 
The Thai art folding of banana leaves : Overlaping design
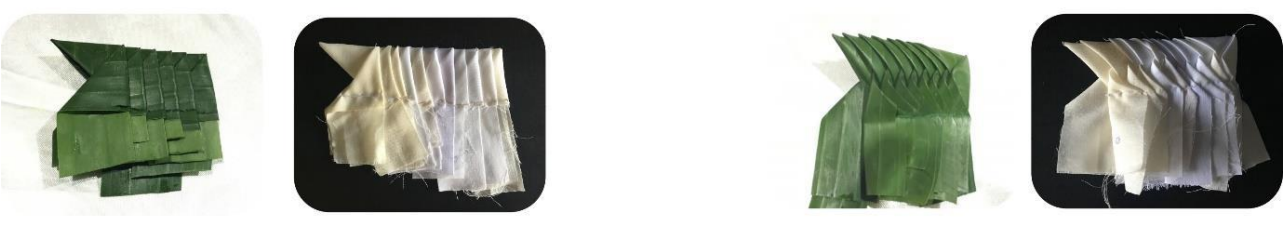

1. Hak kor ma
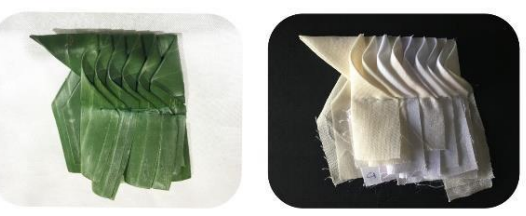

2. Hua kwhan plang
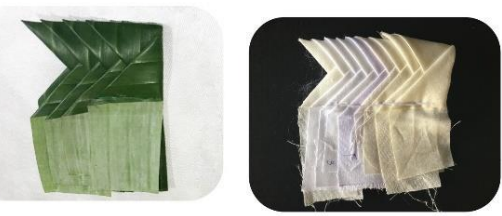

3. Hua nok kor yak

4. Hak kor ma lie pia

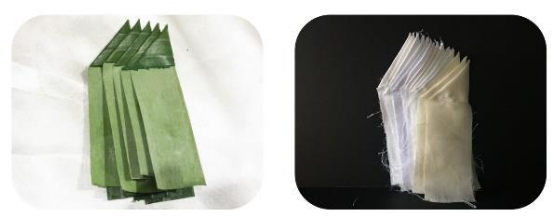

5. Kleab fun pla

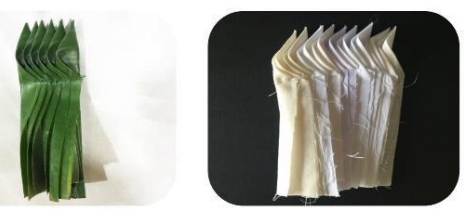

6. Kleab ku larb yam

Figure 2. The Thai art of banana leaves by overlapping method: 1-6

The Thai art folding of banana leaves : Overlaping design

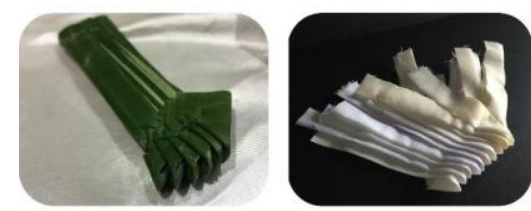

7. Kleab ka ra wake

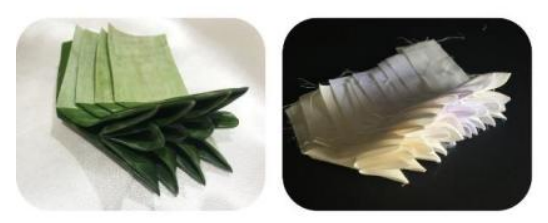

8. Kleab phee seua

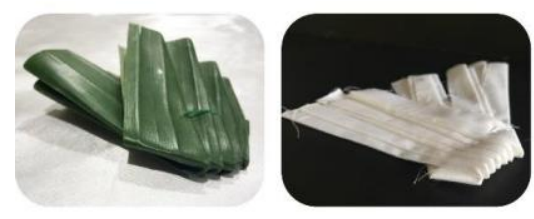

9. Kleab ko sol sroy

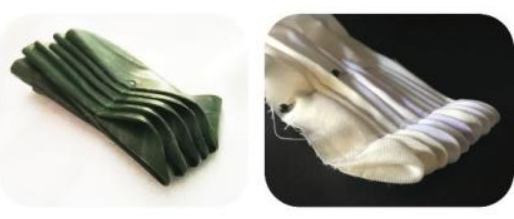

10. Kleab pood tarn

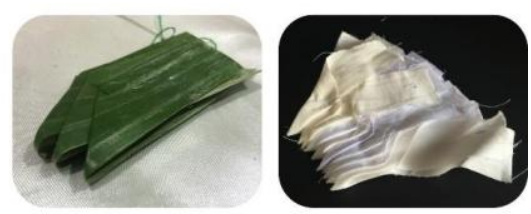

11. Kleab rat cha pruk

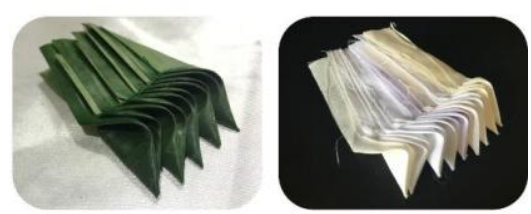

12. Kleab puang ko men

Figure 3. The Thai art of banana leaves by overlapping method: 7-12 


\section{RESULTS}

Historically, clothing is and has been made from many materials. These materials range from grasses to furs to much more elaborate and exotic materials. Some cultures, such as the various people of the Arctic Circle, until recently, made their clothing entirely of prepared and decorated furs and skins. Other cultures have supplemented and replaced leather and skins with cloth.

Cloth is either woven or knitted and can be made from a large variety of fibers, which in turn can be natural, cellulose, or synthetic. Humans have shown extreme inventiveness in devising clothing solutions to environmental hazards and the distinction between clothing and other protective equipment is not always clear-cut; examples include space suit, air conditioned clothing, armor, diving suit, swimsuit, bee-keeper's protective clothing, motorcycle leathers, high-visibility clothing, and protective clothing in general.

Clothing is generally made of cloth. There are many different types of cloth, with different names and uses. Main differences between types of cloth include how the cloth was made (clothing material. In Wikipedia. Retrived August 12, 2016 from https://en.wikipedia.org/wiki/clothingmaterial) so, choose the right fabric is important for the right clothing.

The experiment and practice show the fabric qualification by selected 9 properties suitable for clothing included

1. Good stability

2. Good draping

3. Heat resistance

4. Smoothness

5. Balance

6. Wrinkle

7. Stretch

8. Strong

9. Soft

\section{The wearable fabric are}

1. Natural Fabric

1.1. Cotton

1.2. Linen

1.3. Muslin

1.4. Jute

1.5. Ramie 
2. Man-made fabric

2.1 Polyester

2.2. Nylon

2.3. Organza

2.4. Satin

3. Blended Fabric

3.1. Cotton Spandex

3.2. Linen Visc

Fabric properties for folding

\begin{tabular}{|c|c|c|c|c|c|c|c|c|c|c|c|}
\hline \multirow[t]{2}{*}{ Property } & \multicolumn{5}{|c|}{ Natural Fabric } & \multicolumn{4}{|c|}{ Man-made Fabric } & \multicolumn{2}{|c|}{ Blended Fabric } \\
\hline & Cotton & Linen & Muslin & Jute & Ramie & Polyester & Nylon & Organza & Satin & $\begin{array}{l}\text { Cotton+ } \\
\text { Spandex }\end{array}$ & $\begin{array}{l}\text { Linen+ } \\
\text { Viscose }\end{array}$ \\
\hline $\begin{array}{l}\text { Good } \\
\text { stability }\end{array}$ & $\star \star \star$ & $\star \star$ & $\star \star$ & $\star \star$ & $\star \star$ & $\star \star \star$ & $\star \star$ & $\star$ & $\star$ & $\star \star \star$ & $\star \star \star$ \\
\hline $\begin{array}{l}\text { Good } \\
\text { draping }\end{array}$ & $\star \star x$ & $\star \star \star$ & $\star \star$ & $\star \star$ & $\star \star \star$ & $\star \star \star$ & $\star \star$ & $\star \star \star$ & $\star \star$ & $\star \star \star$ & $\star \star \star$ \\
\hline $\begin{array}{l}\text { Heat } \\
\text { resistance }\end{array}$ & $\star \star \star$ & $\star \star \star$ & $\star \star \star$ & $\star \star$ & $\star \star$ & $\star \star$ & $\star$ & $\star$ & $\star$ & $\star \star \star \star$ & $\star \star$ \\
\hline Smoothness & $\star \star$ & $\star \star x$ & 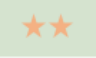 & $\star \star t$ & $\star \star \star$ & $\star \star x$ & $\star \star \star$ & $\star \star \star \star$ & $\star \star \star \star$ & $\star \star \star$ & $\star \star$ \\
\hline Balance & $\star \star \star$ & $\star \star \star$ & $\star \star \star$ & $\star \star \star \star$ & $\star \star \star$ & $\star \star \star$ & $\star$ & $\star$ & $\star$ & $\star \star \star \star$ & $\star \star$ \\
\hline Wrinkle & $\star \star \star$ & $\star$ & $\star \star t$ & $\star$ & $\star$ & $\star \star \star$ & 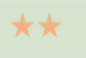 & $\star \star x$ & $\star \star$ & $\star \star \star$ & $\star \star \star x$ \\
\hline Stretch & $\star \star$ & $\star \star$ & $\star \star$ & $\star \star$ & $\star \star$ & $\star \star$ & $\star$ & $\star$ & $\star$ & $\star \star \star$ & $\star \star \star$ \\
\hline Strong & $\star \star \star$ & $\star \star \star$ & $\star \star \star$ & $\star \star \star$ & $\star \star \star$ & $\star \star \star$ & $\star$ & $\star$ & $\star$ & $\star \star \star$ & $\star \star \star$ \\
\hline Soft & $\star \star t$ & $\star \star \star$ & $\star \star$ & $\star \star$ & $\star \star \star x$ & $\star \star \star$ & $\star \star$ & $\star \star \star$ & $\star \star \star$ & $\star \star$ & $\star \star \star \star$ \\
\hline Total & 23 & 22 & 21 & 19 & 19 & 23 & 14 & 15 & 15 & 25 & 22 \\
\hline
\end{tabular}

Figure 4. Fabric properties for folding

From the experiment have founded the best stability are cotton, polyester, cotton+spandex, linen, muslin, jute, ramie, nylon, linen+viscose, organza and satin. The best draping are linen, polyester, cotton+spandex, linen+viscose, cotton, muslin, jute, ramie, nylon, organza, satin. The best heat resistance are cotton, linen, muslin, cotton+spandex, jute, ramie, polyester, linen+viscose, nylon, organza and satin. The best smoothness are organza, satin, cotton, linen, muslin, jute, ramie, polyester, nylon, cotton+spandex, linen+viscose. The balance are cotton, linen, muslin, jute, ramie, polyester, cotton+spandex, linen+viscose, nylon, organza and satin. The best wrinkle are cotton, polyester, cotton+spandex, muslin, nylon, organza, satin, linen+vicose, linen, jute and ramie. The best stretch are cotton+spandex, linen+spandex, cotton, linen, muslin, jute, ramie, polyester, nylon, organza and satin. The best strong are cotton, linen, muslin, jute, ramie, polyester, cotton+spandex, linen+viscose, nylon, organza and satin. The best soft are linen, organza, satin, cotton, muslin, jute, ramie, polyester, nylon and cotton+spandex. Finally, the best result is Polyester, cotton spandex and linen viscose respectively suitable for folding. 


\section{REFERENCES}

Settaman Kanjanakul. 1991. Banana leaves folding idea. Bangkok: Settasilp.

Blue lotus. 2004. A banana matter. Retrieve from

https://owl.english.purdue.edu/owl/resource/560/10/

Maneerat Chantanapalin. 1997. Ngarn bai tong. Bangkok: Faculty of science, Suan dusit College.

William Warren. 1994. Arts and crafts of Thailand. London: Thames and Hudson.

Holly Brackmann. 2006. The surface designer's handbook. Retrieved from

https://books.google.co.th 